Illinois State University

ISU ReD: Research and eData

Theses and Dissertations

$10-13-2013$

\title{
Correlation Of Shoulder And Elbow Kinetics With Ball Velocity In College Baseball Pitchers
}

Eric Post

Illinois State University, egpost@ilstu.edu

Follow this and additional works at: https://ir.library.illinoisstate.edu/etd

Part of the Biomechanics Commons, and the Medicine and Health Sciences Commons

\section{Recommended Citation}

Post, Eric, "Correlation Of Shoulder And Elbow Kinetics With Ball Velocity In College Baseball Pitchers" (2013). Theses and Dissertations. 100.

https://ir.library.illinoisstate.edu/etd/100

This Thesis is brought to you for free and open access by ISU ReD: Research and eData. It has been accepted for inclusion in Theses and Dissertations by an authorized administrator of ISU ReD: Research and eData. For more information, please contact ISUReD@ilstu.edu. 


\section{CORRELATION OF SHOULDER AND ELBOW KINETICS WITH BALL VELOCITY IN COLLEGE BASEBALL PITCHERS}

\section{Eric Griffin Post}

47 Pages

May 2014

Throwing a baseball is an extremely dynamic and violent act that places large amounts of stress on the elbow and shoulder. Due to the repetitive nature of baseball pitching, the accumulation of these forces can often lead to injury. Specific injuries at the elbow and glenohumeral joints have been linked to several kinetic variables that occur throughout the throwing motion. Ulnar collateral ligament sprains of the elbow have been linked to excessive elbow valgus and shoulder external rotation torques occurring during the late-cocking phase of throwing. Shoulder external rotation torque during the late armcocking phase and shoulder distraction forces during the deceleration phase can contribute to tears of the labrum. Additionally, it is believed that the peak distraction force generated during the arm deceleration phase also contributes to rotator cuff pathologies. Unfortunately, very little research has been conducted that directly examines the relationship between ball velocity and these kinetic variables that contribute to various elbow and shoulder pathologies. Therefore, the purpose of this study was to examine the correlation of ball velocity with elbow valgus torque, shoulder external rotation torque, and shoulder distraction force in a group of NCAA Division I collegiate baseball pitchers. 
The pitching kinetics of 67 NCAA Division I collegiate baseball pitchers were analyzed using high-speed motion analysis. Eight electronically synchronized high-speed $(240 \mathrm{~Hz})$ digital cameras were used to track the movement of 26 reflective markers placed over various anatomical landmarks on each participant in order to calculate the values of the kinetic variables examined. After warming up, participants threw fastballs off an indoor pitching mound towards a strike zone target. The average of the 3 highest velocity fastballs thrown for strikes was used for data analysis. The relationships between ball velocity and peak elbow valgus torque, shoulder distraction force, and shoulder external rotation torque were analyzed using a Pearson's correlation coefficient.

A weak positive correlation was found between ball velocity and shoulder distraction force $(r=.26, p=.02)$, but there were no significant correlations between ball velocity and elbow valgus torque $(r=.20, p=.05)$ or ball velocity and shoulder external rotation torque $(r=.10, p=.22)$.

The results of this study indicate that there is little association between ball velocity and several kinetic variables at the elbow and shoulder joints in Division I collegiate baseball pitchers. 
CORRELATION OF SHOULDER AND ELBOW KINETICS WITH BALL VELOCITY IN COLLEGE BASEBALL PITCHERS

\author{
ERIC GRIFFIN POST
}

A Thesis Submitted in Partial Fulfillment of the Requirements for the Degree of

MASTER OF SCIENCE

School of Kinesiology and Recreation

ILLINOIS STATE UNIVERSITY 
CORRELATION OF SHOULDER AND ELBOW KINETICS WITH BALL VELOCITY IN COLLEGE BASEBALL PITCHERS

\author{
ERIC GRIFFIN POST
}

COMMITTEE MEMBERS:

Kevin Laudner, Chair

Todd McLoda

Regan Wong

Keith Meister 


\section{ACKNOWLEDGEMENTS}

I would first like to thank my committee, Drs. Kevin Laudner, Todd McLoda,

Keith Meister, and Mr. Regan Wong, who helped guide me through this process. I would also like to thank my family and friends for their feedback and support. Finally, I would like to thank my fiancé Megan for providing me with motivation and constant encouragement.

E.G.P. 


\section{CONTENTS}

\section{Page}

ACKNOWLEDGEMENTS

CONTENTS

TABLES $\quad$ iv

CHAPTER

I. CORRELATION OF SHOULDER AND ELBOW KINETICS WITH BALL VELOCITY IN COLLEGE BASEBALL PITCHERS 1

Introduction $\quad 1$

Methods $\quad 2$

Participants $\quad 2$

Procedures $\quad 3$

Statistical Analysis $\quad 4$

Results 5

Discussion $\quad 5$

Conclusion $\quad 8$

References $\quad 10$

Tables 14

$\begin{array}{ll}\text { II. } & 15\end{array}$

$\begin{array}{ll}\text { Introduction } & 15\end{array}$

$\begin{array}{ll}\text { Anatomy } & 16\end{array}$

Elbow Joint 16

Glenohumeral Joint $\quad 20$

Biomechanics of Baseball Pitching 26

Overhead Throwing Motion $\quad 26$ 
Elbow and Shoulder Joint Kinetics During the Pitching Motion

Biomechanical Factors Contributing to Injury

Pathomechanics of Medial Elbow Injuries

Pathomechanics of Shoulder Injuries

Influence of Pitch Type and Velocity on Joint Kinetics 


\section{TABLES}

Table $\quad$ Page

1. Correlation of Kinetic Variables with Ball Velocity 14 


\section{CHAPTER I}

\section{CORRELATION OF SHOULDER AND ELBOW KINETICS WITH BALL VELOCITY IN COLLEGE BASEBALL PITCHERS}

\section{Introduction}

Elbow and shoulder injuries among baseball pitchers at all levels of competition are a serious problem, with recent data indicating that injury rates are on the rise. ${ }^{13,15,30,69}$ With approximately 27,000-45,000 collegiate players and over 4.5 million total participants in organized baseball each year, finding ways to reduce the incidence of injury should be a primary objective of sports medicine professionals. ${ }^{19,60,78}$

Specific injuries at the elbow and glenohumeral joints have been linked to several kinetic variables that occur during the throwing motion. Medial elbow injuries, such as ulnar collateral ligament sprains, are often caused by excessive elbow valgus and shoulder external rotation torques occurring during the late-cocking phase of throwing. ${ }^{6,22,27,28,31-33,80,92,93}$ At the glenohumeral joint it is theorized that external rotation torque during the late arm-cocking phase and distraction forces during the deceleration phase contribute to tears of the labrum. ${ }^{27,31,57,82}$ Additionally, it is believed that the peak distraction force generated during the arm deceleration phase also contributes to rotator cuff pathologies. ${ }^{4,10,27,31,53,57,58}$ 
Previous research has linked elbow and shoulder injuries to a variety of risk

factors, including pitch volume, ${ }^{55,62}$ increased innings pitched in a calendar year, ${ }^{29,62}$ increased body mass, ${ }^{62}$ pitch type,${ }^{21,34,55}$ and number of months pitched per year. ${ }^{62}$ More recently, ball velocity has been examined as a possible risk factor for injury. ${ }^{12,28,44,62,72}$ Increased ball velocity has been identified as a risk factor for elbow and shoulder injury in adolescent pitchers ${ }^{27}$ and elbow injury in professional baseball pitchers. ${ }^{5}$ However, very little research has been done to directly examine the relationship between ball velocity and the kinetic variables that have been implicated to contribute to injuries at the elbow and shoulder. Therefore, the purpose of this study was to examine the correlation of ball velocity with elbow valgus torque, shoulder external rotation torque, and shoulder distraction force in a group of NCAA Division I collegiate baseball pitchers. Our hypothesis was that ball velocity would have a moderate positive correlation with elbow valgus torque, shoulder external rotation torque, and shoulder distraction force.

\section{Methods}

Participants

Sixty-seven NCAA Division I collegiate baseball pitchers (age $=19.5 \pm 1.2$ years, height $=186.2 \pm 5.7 \mathrm{~cm}$, mass $=86.7 \pm 7.0 \mathrm{~kg}, 48$ right-handed, 19 left-handed) volunteered to participate in this study. Exclusion criteria included any upper or lower extremity injury within the previous 3 months or any history of upper or lower extremity surgery. 
Procedures

Each participant provided informed consent as approved by the institutional review board before beginning their testing session in a motion analysis laboratory. In addition, height, mass, radius length, humerus length, and medical history were recorded.

Participants then completed their preferred warm-up routine. This routine was not standardized but was chosen by each participant based on their preferred warm up routine, which generally consisted of various static and dynamic stretches, flat ground throwing exercises, and pitching drills. Following warm-up each participant had $1.27 \mathrm{~cm}$ diameter spherical reflective markers (Motion Analysis Corporation, Santa Rosa, California) placed over 26 anatomic landmarks in order to record motion capture data. ${ }^{81,82,85}$ Markers were placed bilaterally at the lateral tip of the acromions, lateral humeral epicondyle, anterior and posterior hip, medial and lateral epicondyle of the femur, medial and lateral malleoli, between the second and third metatarsal heads, and calcaneus. Markers were also placed on the radial and ulnar styloids and third metacarpal on the throwing arm. Additionally, participants wore a hat with markers placed on the left side, right side and top of the head. The markers were secured with electrode collars and tape and participants pitched with no shirt and while wearing spandex shorts in order to prevent excessive motion of the markers. After all markers were secured, the subjects then concluded their warm-up by throwing as many pitches as desired to acclimate themselves to the indoor testing facility.

For data collection, participants pitched off a regulation collegiate indoor pitching mound (Osborne Innovative Products, Inc. Jasper, Indiana). Each participant threw fastballs off the mound towards a regulation distance $(18.4 \mathrm{~m})$ strike zone target. Testing 
was concluded following the collection of 5 representative fastball trials, excluding pitches thrown out of the strike zone and pitches that were self-determined to be not representative of that pitcher's typical throwing mechanics. An investigator stood directly behind the target strike zone in order to record pitch location and measure ball velocity using a radar gun (Stalker Sport, Plano, Texas). The average of the 3 highest velocity fastballs thrown for strikes were used for data analysis.

Each pitch was recorded using 8 electronically synchronized high-speed $(240 \mathrm{~Hz})$ Eagle digital cameras (Motion Analysis Corporation, Santa Rosa, California). ExpertVision software (Eva 6.0, Motion Analysis Corporation) was used to track the reflective markers and three-dimensional coordinate data were determined via direct linear transformation. Joint centers of the shoulder and elbow for both the throwing and non-throwing arm were estimated using previously described methods. ${ }^{32}$ Data were filtered with a Butterworth fourth-order, zero-lag digital filter (cutoff $=10 \mathrm{~Hz}$ ). Kinetic data at the elbow and shoulder were calculated using methods described by Feltner and Dapena. ${ }^{25}$ Forces were expressed as percent body weight and torques were expressed as percent body weight times height in order to normalize data for between-subjects comparison. The peak value for each variable (elbow valgus torque, shoulder external rotation torque, shoulder distraction force) was found by averaging the peak values from the 3 highest velocity fastball trials.

Statistical Analysis

A Pearson's correlation coefficient was generated to determine the relationship between ball velocity and peak elbow valgus torque, shoulder distraction force, and shoulder external rotation torque. Statistical testing was performed with SPSS software 
(IBM SPSS 20.0, Armonk, NY). Statistical significance was established a priori at $p<$ 0.05 .

\section{Results}

Mean and standard deviation values for the group were a ball velocity of $37.3 \pm$ $1.6 \mathrm{~m} / \mathrm{s}(83.5 \pm 3.5 \mathrm{mph})$, elbow valgus torque of $5.7 \pm 1.3 \%$ body weight $*$ height, shoulder distraction force of $110.0 \pm 16.0 \%$ body weight, and shoulder external rotation torque of $5.2 \pm 1.0 \%$ body weight $*$ height.

The results of the correlation analyses are displayed in Table 1. A weak positive correlation was found between ball velocity and shoulder distraction force $(r=.26, p=$ .02). However, there were no significant correlations between ball velocity and elbow valgus torque $(r=.20, p=.05)$ or ball velocity and shoulder external rotation torque ( $r=$ $.10, p=.22)$.

\section{Discussion}

Contrary to our hypothesis, there was only a weak positive correlation between ball velocity and shoulder distraction force. This correlation indicates that very little of the error variance can be explained by ball velocity. The correlations between ball velocity and both elbow valgus torque and shoulder external rotation torque were not significant. These results indicate that there are other variables contributing to kinetic loads at the elbow and shoulder beyond simply throwing at a high velocity.

These findings are contrary to much of the previous research regarding ball velocity and joint kinetics. Fleisig et al. ${ }^{28}$ found that as pitchers went from partial to fulleffort throwing and increased their ball velocity, several kinetic variables including elbow varus torque, shoulder internal rotation torque, and shoulder compressive force also 
increased. ${ }^{28}$ However, these authors also reported that several kinematic variables changed as well, such as maximum glenohumeral external rotation during the late arm cocking phase and elbow flexion angle at the moment of stride foot contact. These alterations in motion create the question of whether the increases in shoulder and elbow forces are a result of the increased ball velocity, altered kinematics, or both. In a separate study, Fleisig et al. ${ }^{32}$ showed that elbow varus torque, shoulder internal rotation torque, and shoulder compressive force increase significantly along with ball velocity as competition level increases. ${ }^{32}$ However, there were also significant kinematic differences between the competition levels, including elbow flexion angle at stride foot contact and maximum upper torso velocity during the arm cocking phase. The weak correlation found in our study suggests that the increased forces seen in these two studies are most likely due to variations in kinematics. Hurd et al. ${ }^{44}$ is the only study, to our knowledge, that directly examined the relationship between ball velocity and kinetics across participants of a similar competitive level. Their results showed that increased ball velocity was positively associated with increased adduction (varus) moments at the elbow among high school pitchers. ${ }^{44}$

Several studies have appeared to link higher ball velocities with injury risk. ${ }^{12,62}$ Bushnell et al. ${ }^{12}$ found a significant association between increased ball velocity and risk of elbow injury in a group of professional baseball pitchers. ${ }^{12}$ Additionally, Olsen et al. ${ }^{62}$ found increased ball velocity to be one of many risk factors for elbow and shoulder injuries in a sample of adolescent pitchers. ${ }^{62}$ However, these previous studies did not assess pitching kinematics. Conversely, our results suggest that other variables play a bigger role than ball velocity in the increased injury risk seen in these studies. 
The concept of certain pitching mechanics being more efficient and contributing to decreases in forces at the elbow and shoulder is well supported by research. ${ }^{1,18,64,77,82,84}$ Aguinaldo et al. ${ }^{1}$ showed that pitchers who displayed late trunk rotation, reduced shoulder external rotation, and increased elbow flexion experienced decreased elbow valgus loads. ${ }^{1}$ Oyama et al. ${ }^{64}$ found pitchers who exhibited excessive contralateral trunk tilt during the pitching motion had increased elbow proximal force, shoulder proximal force, elbow varus moment, and shoulder internal rotation moment. ${ }^{64}$ Interestingly, pitchers with excessive contralateral trunk tilt in that study also threw with significantly greater ball velocity, but those increases in velocity were not significantly correlated with any kinetic variables besides shoulder proximal force. ${ }^{64}$ Increased time within certain phases of the pitching motion, such as the time from stride foot contact to peak pelvis angular velocity, was shown to decrease both joint kinetics and ball velocity. ${ }^{77}$ Decreased shoulder abduction at stride foot contact, decreased peak shoulder horizontal adduction angular velocity, increased elbow flexion, and increased external rotation torque were shown to be responsible for $97 \%$ of the variance in decreasing elbow valgus torque by Werner et al. ${ }^{84}$ In a separate study Werner et al. ${ }^{82}$ identified ten kinematic and kinetic variables that accounted for $89 \%$ of the variance in shoulder distraction force. $<$ sup $>82</$ sup $>$ Finally, Davis et al. ${ }^{8}$ identified five pitching parameters that when successfully performed led to decreases in humeral internal rotation torque and elbow valgus load. ${ }^{8}$ Pitchers of all ages can be instructed in these more efficient mechanics with the goal of increasing performance and reducing the risk of injury.

There are several limitations worth noting in our study. Kinetic calculations are based in part from estimated body segment masses of cadavers, which may not accurately 
represent the body segment masses of the young, asymptomatic participants examined in our study. There is also an unavoidable amount of skin movement where each reflective marker is placed. However, efforts to minimize this movement were conducted and numerous previous studies using similar methodology have been published in various peer-reviewed publications using the same technqiue. ${ }^{1,11,18,21,30,31,37}$ It is also interesting to note that our mean value for shoulder distraction force was higher than had been previously reported. ${ }^{35}$ Werner et al. ${ }^{35}$ found an average peak shoulder distraction force value of $81 \pm 10$ (\% body weight) in a group of 48 college baseball pitchers compared to our value of $110.0 \pm 16.0$ (\% body weight) ${ }^{35}$ However, this difference may be simply attributable to differences in subjects, as the Werner et al. ${ }^{35}$ study recruited from all divisions of NCAA college baseball, not just Division I like in our study. ${ }^{35}$ Furthermore, our study only examined asymptomatic pitchers, limiting the conclusions that can be inferred about injured pitchers. In addition, the results of this study may not apply for youth, adolescent, and professional pitchers. Finally, it is possible that there are many variables contributing to the relationship between joint kinetics and ball velocity, which limits the conclusions that can be drawn from a correlation analysis.

\section{Conclusion}

The results of our study indicate that there is very little association between ball velocity and several kinetic variables at the elbow and shoulder joints in Division I collegiate baseball pitchers. While a weak positive correlation was found between shoulder distraction force and ball velocity, no significant association was seen between ball velocity and elbow valgus torque or shoulder external rotation torque. These results support previous studies that have shown other factors, such as pitching mechanics, 
contribute more significantly to increases in joint kinetics than ball velocity. Future studies are necessary to determine what mechanics are most effective at minimizing kinetic loads at the elbow and shoulder. 


\section{REFERENCES}

1. Aguinaldo AL, Chambers H. Correlation of throwing mechanics with elbow valgus load in adult baseball pitchers. The American journal of sports medicine. 2009;37(10):2043-8.

2. Andrews JR, Carson WG, McLeod WD. Glenoid labrum tears related to the long head of the biceps. The American journal of sports medicine. 1985;13(5):337-41.

3. Anz AW, Bushnell BD, Griffin LP, Noonan TJ, Torry MR, Hawkins RJ. Correlation of torque and elbow injury in professional baseball pitchers. The American journal of sports medicine. 2010;38(7):1368-74.

4. Burkhart SS, Morgan CD, Kibler W Ben. The disabled throwing shoulder: spectrum of pathology Part I: pathoanatomy and biomechanics. Arthroscopy. 2003;19(4):40420 .

5. Bushnell BD, Anz AW, Noonan TJ, Torry MR, Hawkins RJ. Association of maximum pitch velocity and elbow injury in professional baseball pitchers. The American journal of sports medicine. 2010;38(4):728-32.

6. Cain EL, Andrews JR, Dugas JR, et al. Outcome of ulnar collateral ligament reconstruction of the elbow in 1281 athletes: Results in 743 athletes with minimum 2-year follow-up. The American journal of sports medicine. 2010;38(12):2426-34.

7. Conte S, Requa RK, Garrick JG. Disability days in major league baseball. The American journal of sports medicine. 2001;29(4):431-6.

8. Davis JT, Limpisvasti O, Fluhme D, et al. The effect of pitching biomechanics on the upper extremity in youth and adolescent baseball pitchers. The American journal of sports medicine. 2009;37(8):1484-91.

9. Dick R, Sauers EL, Agel J, et al. Descriptive epidemiology of collegiate men's baseball injuries: National Collegiate Athletic Association Injury Surveillance System, 1988-1989 through 2003-2004. Journal of athletic training. 2007;42(2):183-93. 
10. Dun S, Loftice J, Fleisig GS, Kingsley D, Andrews JR. A biomechanical comparison of youth baseball pitches: is the curveball potentially harmful? The American journal of sports medicine. 2008;36(4):686-92.

11. Escamilla R, Barrentine S. Pitching biomechanics as a pitcher approaches muscular fatigue during a simulated baseball game. The American journal of sports medicine. 2007;35(1):23-33.

12. Feltner M, Dapena J. Dynamics of the shoulder and elbow joints of the throwing arm during a baseball pitch. Int J Sport Biomech. 1986;(2):235-259.

13. Fleisig G, Andrews J. Kinetics of baseball pitching with implications about injury mechanisms. The American journal of sports medicine. 1995;23(2):233-9.

14. Fleisig G, Zheng N, Barrentine S, Escamilla R, Andrews J, Lemak L. Kinematic and Kinetic Comparison of Full-Effort and Partial-Effort Baseball Pitching. In: 20th Annual Meeting of American Society of Biomechanics. Atlanta, GA; 1996.

15. Fleisig GS, Andrews JR, Cutter GR, et al. Risk of serious injury for young baseball pitchers: a 10-year prospective study. The American journal of sports medicine. 2011;39(2):253-7.

16. Fleisig GS, Andrews JR. Prevention of elbow injuries in youth baseball pitchers. Sports health. 2012;4(5):419-24.

17. Fleisig GS, Barrentine SW, Escamilla RF, Andrews JR. Biomechanics of overhand throwing with implications for injuries. Sports medicine (Auckland, N.Z.). 1996;21(6):421-37.

18. Fleisig GS, Barrentine SW, Zheng N, Escamilla RF, Andrews JR. Kinematic and kinetic comparison of baseball pitching among various levels of development. Journal of biomechanics. 1999;32(12):1371-5.

19. Fleisig GS, Bolt B, Fortenbaugh D, Wilk KE, Andrews JR. Biomechanical comparison of baseball pitching and long-toss: implications for training and rehabilitation. The Journal of orthopaedic and sports physical therapy. 2011;41(5):296-303.

20. Fleisig GS, Kingsley DS, Loftice JW, et al. Kinetic comparison among the fastball, curveball, change-up, and slider in collegiate baseball pitchers. The American journal of sports medicine. 2006;34(3):423-30.

21. Hurd WJ, Jazayeri R, Mohr K, Limpisvasti O, Elattrache NS, Kaufman KR. Pitch velocity is a predictor of medial elbow distraction forces in the uninjured high school-aged baseball pitcher. Sports health. 2012;4(5):415-8. 
22. Knesek M, Skendzel JG, Dines JS, Altchek DW, Allen A a, Bedi A. Diagnosis and Management of Superior Labral Anterior Posterior Tears in Throwing Athletes. The American journal of sports medicine. 2013;41(2):444-460.

23. Lyman S, Fleisig GS, Andrews JR, Osinski ED. Effect of pitch type, pitch count, and pitching mechanics on risk of elbow and shoulder pain in youth baseball pitchers. The American journal of sports medicine. 2002;30(4):463-8.

24. McLeod WD, Andrews JR. Mechanisms of shoulder injuries. Physical therapy. 1986;66(12):1901-4.

25. Meister K. Injuries to the shoulder in the throwing athlete. Part one:

Biomechanics/pathophysiology/classification of injury. The American journal of sports medicine. 2000;28(2):265-75.

26. NCAA. Student-Athlete Participation: 1981-1982 - 2010-11.; 2011.

27. Olsen SJ, Fleisig GS, Dun S, Loftice J, Andrews JR. Risk factors for shoulder and elbow injuries in adolescent baseball pitchers. The American journal of sports medicine. 2006;34(6):905-12.

28. Oyama S, Yu B, Blackburn JT, Padua D a, Li L, Myers JB. Effect of Excessive Contralateral Trunk Tilt on Pitching Biomechanics and Performance in High School Baseball Pitchers. The American journal of sports medicine. 2013;41(10):2430-2438.

29. Posner M, Cameron KL, Wolf JM, Belmont PJ, Owens BD. Epidemiology of Major League Baseball injuries. The American journal of sports medicine. 2011;39(8):1676-80.

30. Stodden DF, Fleisig GS, McLean SP, Andrews JR. Relationship of biomechanical factors to baseball pitching velocity: within pitcher variation. Journal of applied biomechanics. 2005;21(1):44-56.

31. Urbin M a, Fleisig GS, Abebe A, Andrews JR. Associations between timing in the baseball pitch and shoulder kinetics, elbow kinetics, and ball speed. The American journal of sports medicine. 2013;41(2):336-42.

32. USA Baseball. Final Report. 2009. Available at: http://web.usabaseball.com/downloads/2009/final_report.txt.

33. Werner SL, Fleisig GS, Dillman CJ, Andrews JR. Biomechanics of the elbow during baseball pitching. The Journal of orthopaedic and sports physical therapy. 1993;17(6):274-8. 
34. Werner SL, Guido J a, Delude N a, Stewart GW, Greenfield JH, Meister K. Throwing arm dominance in collegiate baseball pitching: a biomechanical study. The American journal of sports medicine. 2010;38(8):1606-10.

35. Werner SL, Guido JA, Stewart GW, McNeice RP, VanDyke T, Jones DG. Relationships between throwing mechanics and shoulder distraction in collegiate baseball pitchers. Journal of shoulder and elbow surgery. 2007;16(1):37-42.

36. Werner SL, Murray TA, Hawkins RJ, Gill TJ. Relationship between throwing mechanics and elbow valgus in professional baseball pitchers. Journal of shoulder and elbow surgery. 2002;11(2):151-5.

37. Werner SL, Suri M, Guido J a, Meister K, Jones DG. Relationships between ball velocity and throwing mechanics in collegiate baseball pitchers. Journal of shoulder and elbow surgery. 2008;17(6):905-8.

38. Zheng N, Barrentine SW. Biomechanics and motion analysis applied to sports. Physical medicine and rehabilitation clinics of North America. 2000;11(2):30922.

39. Zheng N, Fleisig GS, Barrentine SW, Andrews JR. Biomechanics of Pitching. In: Hung G, Pallis J, eds. Biomedical Engineering Principles in Sports. 1st ed. Kluwer Academic/Plenum Publishers; 2004:209-256. 


\section{Tables}

TABLE 1. Correlation of Kinetic Variables with Ball Velocity

\begin{tabular}{lccc}
\hline Variable & Mean \pm SD & $\boldsymbol{r}$ & $\boldsymbol{p}$ \\
\hline Elbow valgus torque & $5.7 \pm 1.3(\% \mathrm{BW} * \mathrm{HGT})$ & .20 & .05 \\
Shoulder distraction force & $110.0 \pm 16.0(\% \mathrm{BW})$ & .26 & $.02 *$ \\
Shoulder external rotation torque & $5.2 \pm 1.0(\% \mathrm{BW} * \mathrm{HGT})$ & .10 & .22 \\
\hline
\end{tabular}

*Statistically significant correlation $(p<.05)$. 


\section{CHAPTER II}

\section{LITERATURE REVIEW}

\section{Introduction}

The baseball pitching motion is perhaps the most dynamic motion in all of sports, requiring the body to generate incredible rotational velocities and imparting large forces on both the elbow and the shoulder joints. ${ }^{28,55,61,75,79}$ As such, the bones, capsules, ligaments, and muscles that constitute the anatomy of the elbow and shoulder joints must withstand these large forces or injury will occur. Therefore, it is no surprise that elbow and shoulder injuries among baseball pitchers at all levels of competition are a serious problem, with recent data indicating that injury rates are on the rise. ${ }^{11,13,27,65} \mathrm{With}$ approximately $27,000-45,000$ college players and over 4.5 million total participants in

organized baseball each year, ${ }^{17,57,73}$ finding ways to reduce the incidence of injury is a primary objective of sports medicine professionals.

Multiple risk factors for injury in baseball pitchers have been identified, including increased pitch volume, increased innings pitched per calendar year, increased body mass, pitch type, and number of months pitched per year. ${ }^{19,26,31,52,59}$ More recently, ball velocity has been examined as a possible risk factor for injury. ${ }^{10,25,41,59,68}$ Increased ball velocity has been found to be associated with elbow injury in professional baseball pitchers. ${ }^{10}$ Additionally, in adolescent pitchers increased ball velocity was shown to be a 
risk factor for elbow and shoulder injuries. ${ }^{59}$ Studies have indicated that various kinetic variables such as elbow varus torque, shoulder compressive force, and shoulder anterior force increase within subjects along with ball velocity as effort level is increased. ${ }^{25,68}$ However, only one study to our knowledge has directly examined the relationship between ball velocity and elbow kinetics across subjects. ${ }^{41}$ This study found a positive association between elbow adduction (varus) moment and ball velocity in a group of high school pitchers. ${ }^{41}$ Additionally, there has been little research examining the relationship between shoulder kinetics and ball velocity.

\section{Anatomy}

Elbow Joint

The elbow joint complex is formed by the distal humerus, proximal radius, and proximal ulna. ${ }^{12,33,35,40,70}$ The elbow complex actually consists of three separate articulations: the humeroulnar, radiohumeral (or radiocapitellar), and proximal radioulnar joints. ${ }^{4,33,35,40,70}$

The humeroulnar joint is a diarthrodial, uniaxial, hinge joint that provides the motions of flexion and extension and is formed by the articulation between the proximal ulna and distal humerus. ${ }^{43,35,70}$ The humeroulnar joint has been described as a modified hinge joint due to a small amount of internal and external rotation that occurs at the endrange of flexion and extension. ${ }^{2,70}$ The radiohumeral (or radiocapitellar) joint is formed by the articulation of the radial head and a part of the distal humerus known as the capitellum..$^{4,33,35,70}$ The radiohumeral joint is a diarthrodial, uniaxial joint, similar to the humeroulnar joint, but it is both a hinge and pivot joint due to its function in assisting the flexion and extension motion of the humeroulnar joint as well as the pronation and 
supination motion of the proximal radioulnar joint. ${ }^{33,70}$ The proximal radioulnar joint is a diarthrodial, uniaxial, pivot joint that consists of the convex radial head rotating within the concave radial notch of the ulna and works in conjunction with the distal radioulnar joint to produce pronation and supination of the forearm..$^{33,35,70}$

Static stability of the elbow joint is created not only by the highly congruous bony anatomy, but also from ligament complexes on both the medial and lateral sides of the joint. ${ }^{12,33,35,40,56,70}$ The lateral ligament complex consists of the radial collateral ligament, lateral ulnar collateral ligament, accessory lateral collateral ligament, and the annular ligament. $^{33,35,40,70}$ The radial collateral, lateral ulnar collateral, and accessory lateral collateral ligaments all provide stability against varus stresses. ${ }^{33,35,40,56,70}$ In addition, the lateral ulnar collateral ligament prevents posterolateral rotary instability of the elbow. ${ }^{33,35,40,70}$ The annular ligament is a tight fibrous band that surrounds the radial head and aids the radius in smooth pronation and supination in addition to preventing distal distraction of the radial head..$^{33,35,70}$

Of primary concern in the overhead athlete is the medial ligamentous complex of the elbow, also known as the ulnar collateral ligament (UCL). ${ }^{4,12,32,33,35,37,40,56,70}$ The UCL is made up of three ligament bundles: the anterior oblique ligament, the posterior oblique ligament, and the transverse ligament. ${ }^{12,32,33,35,37,40,70}$ The anterior oblique ligament is the primary stabilizer against valgus stress at the elbow between 20 and $120^{\circ}$ of elbow flexion, making it the main ligament stressed during the throwing motion. ${ }^{12,32,37,40}$ It originates on the inferior surface of the medial epicondyle of the humerus and inserts on the coronoid process of the ulna. ${ }^{33,35,37,70}$ The anterior oblique ligament can be further divided into the anterior and posterior bands. ${ }^{32,37,70}$ The anterior band is taut and resists 
valgus stress until about $90^{\circ}$ of elbow flexion and the posterior band is taut and resists valgus stress from 60 to $120^{\circ}$ of elbow flexion..$^{32,37,70}$ The posterior oblique ligament of the UCL originates on the medial epicondyle of the humerus and inserts on the olecranon process of the ulna. ${ }^{33,35,37,70}$ The posterior oblique ligament is taut in elbow flexion after $90^{\circ}$ but does not significantly contribute to valgus stability unless the anterior oblique ligament is completely ruptured. ${ }^{32,33,35,37,70}$ The transverse ligament both originates and inserts on the ulna and thus does not provide any support against valgus stress at the elbow. $^{32,33,35,37,70}$

There are four main groups of muscles that cross the elbow joint: the elbow extensors, the elbow flexors, the wrist extensor-supinator group, and the wrist flexorpronator group. ${ }^{4,33,40,70}$ The elbow extensors are found posteriorly and include the triceps brachii and anconeus muscles. ${ }^{43,40,70}$ The elbow flexors are found on the anterior aspect of the elbow and include the biceps brachii, brachioradialis, and the brachialis. ${ }^{4,33,40,70}$ The wrist extensor-supinator group originates on or near the lateral epicondyle of the humerus and includes the extensor carpi radialis brevis and longus, supinator, extensor digitorum, extensor carpi ulnaris, and extensor carpi minimi. ${ }^{4,33,40,70}$ Finally, the wrist flexor-pronator group is found on the medial aspect of the elbow originating on or near the medial epicondyle. ${ }^{4,33,40,70}$ This group includes the pronator teres, flexor carpi radialis, palmaris longus, flexor carpi ulnaris, and flexor digitorum superficialis., $43,40,70$ Collectively, the flexor-pronator group provides dynamic stability against valgus stress at the elbow. ${ }^{12,37,40,62}$ In particular, the flexor carpi ulnaris has been shown to be the primary dynamic stabilizer to valgus stress at the elbow, with the flexor digitorum superficialis serving as the secondary dynamic stabilizer. ${ }^{40,62}$ 
There are three primary nerves that cross the elbow joint: the radial nerve, the median nerve, and the ulnar nerve. ${ }^{35,70}$ The radial nerve crosses over the lateral aspect of the elbow joint between the brachioradialis and brachialis muscles. ${ }^{35,70}$ The radial nerve then continues distally under the brachioradialis muscle and provides sensation to the dorsolateral wrist and dorsal surface of the first three and a half digits. ${ }^{4,35,70}$ It innervates the triceps, anconeus, and the majority of the extensor-supinator group. ${ }^{4,35,70}$ The median nerve crosses the elbow anteriorly just laterally to the brachial artery. ${ }^{35,70}$ It then passes through the two heads of the pronator teres before travelling down the anterior forearm and finally through the carpal tunnel into the hand. ${ }^{35,70}$ The median nerve is responsible for motor innervation of the flexor-pronator group with the exception of flexor carpi ulnaris and flexor digitorum profundus. ${ }^{4,35,70}$ It also provides sensory function to the lateral palmar aspect of the hand and the palmar surface of the first three and a half digits. $^{4,35,70}$ The ulnar nerve passes through the cubital tunnel on the medial aspect of the elbow before passing through the two heads of the flexor carpi ulnaris during its path to the hand..$^{35,70}$ The olecranon process of the ulna and the medial epicondyle of the humerus form the cubital tunnel, with the cubital tunnel retinaculum serving as the roof of the tunnel. ${ }^{35,70}$ In elbow flexion the ulnar nerve is compressed within the tunnel and placed under tension around the medial epicondyle, which subjects the nerve to trauma with valgus forces at the elbow. ${ }^{4,35,70}$ This puts the ulnar nerve at risk for injury in overhead athletes. ${ }^{4,35,70}$ The ulnar nerve innervates the flexor carpi ulnaris and flexor digitorum profundus and provides sensory function to the medial dorsal and palmar aspects of the hand and last digit and a half., 4,35,70 


\section{Glenohumeral Joint}

The shoulder joint technically consists of three joints: the glenohumeral joint, the sternoclavicular joint, and the acromioclavicular joint. ${ }^{15,36,71}$ However, the glenohumeral joint is often referred to as the true shoulder joint and is of primary concern when discussing the overhead athlete. ${ }^{15}$ The glenohumeral joint consists of two bones, the humerus and the scapula. ${ }^{15,36,71}$ Together with the clavicle these bones comprise the shoulder girdle, which is attached to the axial skeleton via the sternoclavicular joint. ${ }^{15,36,71}$ The glenohumeral joint is a ball and socket joint formed by the articulation of the humeral head with the glenoid fossa of the scapula. ${ }^{15,36,71}$ The glenohumeral joint is considered the most mobile joint in the human body. ${ }^{36,71,84}$ The joint is capable of flexion and extension, abduction and adduction, internal and external rotation, horizontal abduction and horizontal adduction, and circumduction. ${ }^{15,36,71}$ The combination of these motions allows for the incredible amount of mobility seen at the glenohumeral joint. ${ }^{15,36,71,84}$ However, this excessive mobility comes at the expense of glenohumeral stability. ${ }^{15,36,71,84}$ The humeral head is approximately three times the size of the glenoid fossa, creating an inherent lack of bony stability at this joint. ${ }^{15,36,71,84}$ Due to this lack of bony stability, the passive and dynamic structures of the glenohumeral joint play an important role in providing stability to the joint. ${ }^{15,23,36,39,67,71,72,80,84}$

Several passive structures contribute to stability at the glenohumeral joint. $^{15,23,36,67,71,72,80}$ The glenoid labrum is a fibrocartilage rim attached to the glenoid fossa that serves to deepen the shallow glenoid fossa and increase glenohumeral joint stability. ${ }^{15,36,71,80}$ The glenoid labrum blends with the glenohumeral ligaments and serves as the attachment point of the long head of the biceps tendon. ${ }^{15,36,71,80}$ Damage to the 
glenoid labrum can result in recurrent instability at the shoulder due to disruptions of these attachments to the glenohumeral ligaments. ${ }^{71,80}$ The humeral head is surrounded by a joint capsule that is roughly twice the volume of the humeral head, which allows for a wide range of motion at the glenohumeral joint. ${ }^{15,36,71,80}$ The capsule originates from the glenoid fossa and glenoid labrum and is reinforced by the glenohumeral ligaments and the tendons of the rotator cuff muscles..$^{15,36,71,80}$ The negative intra-articular pressure created within the joint capsule creates a suction-cup like effect that contributes to joint stability. ${ }^{15,80}$

There are three glenohumeral joint ligaments: the superior glenohumeral ligament (SGHL), middle glenohumeral ligament (MGHL) and inferior glenohumeral ligament (IGHL). ${ }^{15,23,36,67,71,72,80}$ These three ligaments are not true ligaments but rather thickenings in the joint capsule. ${ }^{15,36,67,71,80}$ The SGHL originates at the superior glenoid tubercle, the superior glenoid labrum, and the base of the coracoid process and attaches to the humerus superior to the lesser tuberosity. ${ }^{15,36,71}$ The SGHL prevents inferior translation and external rotation of the glenohumeral joint with the humerus in $0^{\circ}$ of abduction. ${ }^{15,23,71,72,80}$ The MGHL originates on the anterior border of the glenoid fossa and inserts on the medial aspect of the lesser tuberosity. ${ }^{15,36,71}$ The MGHL functions to prevent glenohumeral external rotation with the humerus abducted to $45^{\circ} .{ }^{15,23,71,72,80}$ The IGHL is made up of an anterior and posterior band, with an axillary pouch connecting the two bands and running underneath the humeral head like a hammock. ${ }^{15,36,71,80}$ The anterior band originates on the anteroinferior labrum and attaches at the lesser tuberosity of the humerus. ${ }^{15,36,71}$ The anterior band serves to stabilize against anterior and inferior humeral head translation when the humerus is in the throwing position of approximately $90^{\circ}$ of 
abduction and external rotation. ${ }^{15,23,71,72,80}$ The posterior band of the IGHL originates on the posteroinferior labrum and attaches to the neck of the humerus. ${ }^{15,36,71}$ It serves to prevent glenohumeral internal rotation with the humerus abducted $90^{\circ} \mathrm{s}$ and also prevents inferior displacement of the humeral head with the humerus at $90^{\circ}$ of abduction. ${ }^{15,23,71,72,80}$

There are several unique anatomical adaptations seen in the glenohumeral joint of the overhead athlete. ${ }^{6-8,14,47,60,64,66}$ Athletes who participate in a large volume of overhead activities, such as baseball pitchers, have been shown to have bilateral differences in glenohumeral range of motion. ${ }^{6-8,14,47,60,64,66}$ More specifically, these athletes present with an increase in glenohumeral external rotation with a concurrent decrease in glenohumeral internal rotation in their throwing arms. ${ }^{6-8,14,47,60,64,66}$ It is believed that these differences in range of motion are due to both osseous and soft-tissue adaptations. ${ }^{6,8,14,47,60,64,66}$ It has been shown that athletes who participate in repetitive overhead activities have increased retroversion of the humeral head and glenoid in their throwing arm compared with their non-throwing arm and compared to control groups that did not participate in overhead activities. ${ }^{8,14,47,60,64,66}$ This increased retroversion allows for the humeral head to remain in contact with the glenoid through a larger range of external rotation before being constrained by the anterior capsule. ${ }^{14,47,60,64,66}$ It has also been theorized that tightness of the posterior glenohumeral joint capsule and posterior rotator cuff musculature also contributes to changes in range of motion. ${ }^{8,47}$ It is believed that the repetitive microtrauma of throwing creates a contracture of the posterior joint capsule and rotator cuff due to the build up of fibrotic scar tissue. ${ }^{8,47}$ This contracture of the posterior soft tissue is 
believed to shift the humeral head into a position of increased external rotation and decreased interrnal rotation. ${ }^{8,47}$

The glenohumeral joint depends on several muscles to provide the wide range of motions seen at the joint and to provide dynamic stability. ${ }^{15,36,71,80,84}$ The rotator cuff muscle group consists of four muscles that originate on the scapula and insert on the humeral head. ${ }^{15,36,71,80}$ The four muscles of the rotator cuff are the supraspinatus, infraspinatus, teres minor, and subscapularis. ${ }^{15,36,71,80}$ As a group, the rotator cuff muscles work together to provide dynamic stability to the glenohumeral joint by compressing and centering the humeral head within the glenoid. ${ }^{15,36,71,80,84}$ Additionally, contraction of the rotator cuff depresses the humeral head during humeral abduction to ensure that the humeral head passes smoothly under the acromion. ${ }^{15,36,71,80,84}$ The supraspinatus, originating from the supraspinous fossa of the scapula and inserting on the superior facet of the greater tuberosity on the humerus, acts to abduct the arm in the plane of the scapula. ${ }^{15,36,71,80}$ The infraspinatus originates in the infraspinous fossa of the scapula and inserts on the middle facet of the greater tuberosity on the humerus. ${ }^{15,36,71,80}$ It functions along with the teres minor to externally rotate the humerus. ${ }^{15,36,71,80}$ The teres minor originates on the axillary border of the scapula and inserts on the inferior facet of the greater tuberosity on the humerus. ${ }^{15,36,71,80}$ The subscapularis is the only rotator cuff muscle originating on the anterior aspect of the scapula. ${ }^{15,36,71,80}$ It runs from the subscapular fossa of the scapula and inserts on the lesser tuberosity of the humerus and serves to internally rotate the humerus. ${ }^{15,36,71,80}$ Although not technically a part of the rotator cuff muscle group, the long head of the biceps also deserves mention as a dynamic stabilizer of the glenohumeral joint. ${ }^{36,71}$ The long head of the biceps originates from the 
glenoid labrum near the supraglenoid tubercle and runs through the intertubecular groove to merge with the short head of the biceps and form the muscle belly of the biceps brachii, ultimately inserting into both the radial tuberosity and bicipital aponeurosis. $3,36,50,54,71,80,81$ During the late cocking phase of throwing the long head of the biceps contracts and prevents anterior translation and excessive external rotation of the humeral head. ${ }^{36,71}$

There are several more muscles acting at the glenohumeral joint beyond just the rotator cuff muscles. ${ }^{15,36,71}$ The deltoid muscle can be divided into anterior, middle, and posterior segments, which originate on the lateral clavicle, acromion process, and spine of the scapula, respectively. ${ }^{36,71}$ All three segments of the deltoid insert on the deltoid tuberosity of the humeral head and as a group act to abduct the humerus. ${ }^{36,71}$ Individually, the anterior deltoid flexes the humerus, the middle deltoid abducts the humerus, and the posterior deltoid extends the humerus. ${ }^{36,71}$ The pectoralis major originates on the medial clavicle, the sternum, and the fifth and sixth ribs and inserts on the lateral lip of the bicipital groove of the humerus. ${ }^{36,71}$ Pectoralis major acts to adduct, horizontally adduct, and internally rotate the humerus. ${ }^{36,71}$ The latissimus dorsi adducts, extends, and internally rotates the humerus. ${ }^{36,71}$ It has a wide origin across the lumbar spine, thoracolumbar fascia, and iliac crest and attaches on the intertubercular groove of the humerus. ${ }^{36,71}$ The teres major is also known as the "little lat" muscle due to its similar action of humeral adduction, extension, and internal rotation. ${ }^{36,71}$ Its origin is at the inferior angle of the scapula and it inserts on the medial lip of the intertubercular groove of the humerus. ${ }^{36,71}$ Finally, the coracobrachialis originates on the coracoid process and 
inserts on the anteromedial surface of the central humerus. ${ }^{36,71}$ The coracobrachialis serves as a flexor and adductor of the glenohumeral joint. ${ }^{36,71}$

Although not technically a true joint, the scapulothoracic articulation is vital in proper function of the glenohumeral joint and thus deserves mention. ${ }^{15,36,48,49,71,80}$ The articulation consists of the space between the convex posterior thoracic rib cage and the concave surface of the anterior scapula. ${ }^{71}$ The scapula serves as the base from which humeral movement occurs, so without proper scapulothoracic function, proper glenohumeral joint motion will not occur. ${ }^{48,49,71,80}$ The muscles of the scapulothoracic joint must dynamically stabilize the scapula to provide optimal length-tension relationships for the muscles of the glenohumeral joint. ${ }^{48,49,80}$ The scapulothoracic muscles also function to provide proper scapular motion in order to ensure that the humeral head clears the acromion process during glenohumeral elevation. ${ }^{15,48,49,71}$ The scapulothoracic muscle group consists of the trapezius, the rhomboids, levator scapulae, serratus anterior, and pectoralis minor. ${ }^{36,49,71,80}$

The trapezius is a large kite-shaped muscle on the upper back consisting of upper, middle, and lower portions. ${ }^{36,71}$ Each of these portions of the trapezius has unique functions and should thus be considered as if it were a separate muscle. ${ }^{36,71}$ The upper trapezius fibers originate from the occipital protuberance and the nuchal ligament and insert on the lateral clavicle, acromion process, and spine of the scapula. ${ }^{36,71}$ These fibers act to upwardly rotate and elevate the scapula. ${ }^{36,71,80}$ The fibers of the middle trapezius originate from the spinous processes of C-7 through T-3 and inserts on the acromion process and the lateral spine of the scapula. ${ }^{36,71}$ The middle trapezius is responsible for retraction of the scapula. ${ }^{36,71,80}$ Finally, the lower fibers of the trapezius originate on the 
spinous processes of T-3 through T-12 and inserts on the medial spine of the scapula. ${ }^{36,71}$ The lower trapezius plays an important role in the overhead thrower, as it is responsible for upward rotation of the scapula as the humerus abducts above $90^{\circ} .^{48,49}$ It also works to depress and retract the scapula. ${ }^{36,71,80}$ The rhomboids consist of rhomboid major and rhomboid minor and together they work to elevate and retract the scapula. ${ }^{36,71,80}$ Additionally, rhomboid major assists in downward rotation of the scapula. ${ }^{36,71,80}$ Rhomboid major runs from the spinous processes of T2 through T5 to the superior medial angle of the scapula. ${ }^{36,71}$ Rhomboid minor originates from the spinous processes of C-7 and T-1 to insert on the scapula near the medial border of the scapular spine. ${ }^{36,71}$ As its name implies, the levator scapula elevates the scapula, as well as assisting in scapular downward rotation. ${ }^{36,71,80}$ The transverse processes of $\mathrm{C}-1$ through $\mathrm{C}-4$ serve as the origin point for the levator and it inserts on the superior angle of the scapula. ${ }^{36,71}$ The fan-like serratus anterior muscle originates from the anterior aspects of the first nine ribs to insert along the entire medial border of the scapula. ${ }^{36,71}$ The main role of the serratus anterior is fixation of the vertebral border of the scapula onto the thorax. ${ }^{36,71}$ Additionally, the muscle assists in scapular protraction and upward rotation. ${ }^{36,71,80}$ A final scapulothoracic muscle worth mentioning is pectoralis minor. Originating from the anterior aspects of ribs 3 through 5 and inserting on the coracoid process of the scapula, the pectoralis minor protracts and downwardly rotates the scapula. ${ }^{36,71,80}$

\section{Biomechanics of Baseball Pitching}

Overhead Throwing Motion

The act of pitching a baseball is one of the most dynamic motions in all of sports, requiring total body coordination in order to impart the baseball with the greatest possible 
velocity. ${ }^{28,55,61,75,79}$ During the acceleration phase of the throwing motion, the humerus internally rotates at over $7000^{\circ}$ second, making it the highest recorded angular velocity in any human motion..$^{25,55,61,79}$ The baseball pitching motion utilizes the summation of momentum principle to generate and transfer energy from larger body segments such as the legs and torso up the kinetic chain to smaller segments such as the shoulder, wrist, hand, and ultimately imparting this energy to the ball. ${ }^{28,55,61}$ The pitching motion is broken down into six discrete phases: wind-up, stride, arm-cocking, arm acceleration, arm deceleration, and follow-through. ${ }^{18,21,28,55,75,79}$

The wind-up phase begins when the athlete initiates motion and ends when maximum leg lift of the stride leg is achieved. ${ }^{18,21,28,55,61,75}$ The purpose of the wind-up phase is to prepare the pitcher to begin his motion towards the plate. ${ }^{28,55,61,75}$ The pitcher begins by facing home plate and steps back with the stride leg while the foot of the stance leg is aligned parallel against the pitching rubber. ${ }^{18}$ The pitcher then shifts their weight onto the stance leg and flexes the stride leg hip in preperation for the pitcher to begin their motion towards the plate. ${ }^{18,75}$ Muscle activation of the upper extremities is very low during this phase as the majority of the motions occurring are in the lower extremities. ${ }^{21,28,43,55,75}$

The stride phase begins at maximum leg lift of the stride leg and ends at the moment of stride foot contact. ${ }^{18,21,28,55,75}$ The purpose of the stride phase is to generate linear velocity of the body towards home plate. ${ }^{18,28}$ During this phase the hands separate as both shoulders abduct and the throwing shoulder begins to externally rotate. ${ }^{18,43,75}$ By the moment of stride foot contact the ground the throwing arm should be in the "90-90" position of $90^{\circ}$ shoulder abduction, $90^{\circ}$ shoulder external rotation, and $90^{\circ}$ of elbow 
flexion. ${ }^{16,28,55,61,79}$ During this phase the deltoid and supraspinatus are highly active in order to adbuct the shoulder. ${ }^{21,28,55}$ Additionally, the teres minor and infraspinatus begin to activate in order to compress and stabilize the humeral head within the glenoid. ${ }^{21,28,55}$ The trapezius and serratus anterior are also highly active as they upwardly rotate the scapula to accommodate the abduction of the humerus. ${ }^{21,28}$

The purpose of the arm-cocking phase is to position the shoulder in maximum external rotation and retraction in preperation for acceleration of the arm. ${ }^{21,28}$ The armcocking phase begins at stride foot contact and ends when maximum external rotation of the shoulder is reached. ${ }^{21,28,55,75}$ While the shoulder is externally rotating and "cocking back" during this phase the rest of the body begins to move forwards towards the plate. ${ }^{18,21,28,61,75}$ At foot contact the quadriceps contracts to stop knee flexion and stiffen the stride leg. ${ }^{28}$ As the stride foot makes contact and the stride leg is stabilized, the pelvis begins to rotate towards the plate, with torso rotation occurring soon afterwards. ${ }^{18,21,28,61,75}$ The rhomboids, serratus anterior, trapezius, and pectoralis minor are highly active during this phase in order to properly position and stabilize the scapula so it can serve as a stable base for the humerus. ${ }^{21,28,43}$ The rotator cuff, long head of the biceps, and triceps are all very active during this phase in order to stabilize the glenohumeral joint and resist the large distractive forces generated as the arm cocks back while the pelvis and torse rotate forward..$^{21,28,55}$ The pectoralis major, subscapularis, and latissimus dorsi all are highly active during this phase to provide an internal rotation torque which slows the rapid external rotation of the glenohumeral joint. ${ }^{21,28,43,55}$ At the elbow, the wrist flexor-pronator group and the triceps and anconeus are all highly active in order to provide a varus torque to counteract the large valgus torque at the elbow seen 
at maximum shoulder external rotation. ${ }^{28,75}$ At the end of the arm-cocking phase the shoulder will typically be externally rotated between $150-180^{\circ}$ and abducted between 90 $100^{\circ}$ with the elbow flexed between $90-100^{\circ}$ as well..$^{21,28,55,61}$

The arm acceleration phase consists of the time between maximum external rotation of the shoulder and ball release. ${ }^{18,21,28,61,75}$ During this brief time peiod, typically lasting only $2 \%$ of the total time of the pitching motion, the arm begins to rapidly internally rotate as the kinetic energy generated by the rotation of the pelvis and torso is transferred to the shoulder. ${ }^{28,61}$ The rectus abdominus and obliques are highly active during this phase as they flex the trunk forward before ball release. ${ }^{28}$ The velocity of this shoulder internal rotation has been measured to be anywhere in the range of $3340 \mathrm{~m} / \mathrm{s}$ to $9198 \mathrm{~m} / \mathrm{s}$, making it the fastest recorded human motion. ${ }^{21,55,61}$ The shoulder internal rotators, consisting of the subscapularis, pectoralis major, and latissimus dorsi, are highly active during this phase in order to produce this internal rotation velocity. ${ }^{21,28,43,55}$ The rhomboids, trapezius, and serratus anterior continue to have a high level of activity in order to stabilize the scapula. ${ }^{21,28,43,55}$ The energy produced by the sequential rotation of the pelvis, torso, and shoulder continues to travel up the kinetic chain, causing rapid elbow extension followed by wrist flexion and pronation, which propels the ball towards the target. ${ }^{18,28,61}$ This rapid elbow extension is controlled by large eccentric activity of the biceps brachii, brachialis, and brachioradialis. ${ }^{28,75}$ The contraction of the long head of the biceps brachii also serves to help stabilize and provide a compressive force to the glenohumeral joint. ${ }^{21,28}$

The next phase is the arm deceleration phase, which serves to slow down the throwing arm and safely dissipate any energy that was not transferred to the ball at ball 
release. $^{21,28,55,61}$ The deceleration phase begins at ball release and ends when the shoulder reaches maximum internal rotation. ${ }^{21,28,55,61}$ During this phase the shoulder remains abducted at around $90^{\circ}$ and begins to horizontally adduct across the body. ${ }^{28,55,61}$ The posterior shoulder musculature, including the infraspinatus, teres minor, and latissimus, are extemely active during this phase as they eccentrically contract to slow both humeral internal rotation and horizontal adduction..$^{21,28,43,55,61}$ The rapid elbow extension seen in the acceleration phase is slowed by continued eccentric contraction of the elbow flexors, with the elbow stopping just short of full extension. ${ }^{28}$ The wrist extensors are also highly active during this phase as they work to eccentrically slow wrist flexion. ${ }^{75}$

The final phase of the throwing motion is the follow-through phase. ${ }^{18,28,55,61,75,79}$ This phase begins at maximum shoulder internal rotation and ends when the arm has stopped moving across the body and the motion of the pitcher's body has ceased. ${ }^{18,28,55,61,75}$ The purpose of the follow-through phase is to finish dissipating the stress and energy from the previous phases and to allow the pitcher to get into a good defensive position. ${ }^{18,28,75}$ During this phase shoulder abduction decreases and horizontal adduction increases as the arm lowers and crosses the body. ${ }^{18,28,55,61}$ Muscle activation at the shoulder and elbow gradually decreases to resting levels. ${ }^{28,55}$ Additionally, the stance leg is lifted and carried forward to land next to the stride leg, putting the pitcher in a balanced stance facing the plate. ${ }^{55,75}$

Elbow and Shoulder Joint Kinetics During The Pitching Motion

Due to the extremely dynamic and violent nature of the pitching motion, both the elbow and shoulder are subject to large forces and torques throughout the delivery. ${ }^{24,28,75,85}$ It is important to understand when and where these forces occur within 
the pitching motion in order to better understand the pathomechanics of specific injuries, which will be discussed later. ${ }^{24,28,29,75,85}$ Since forces at the elbow and shoulder are minimal during the first two phases of pitching (wind-up and stride), only the forces seen during the final four phases (arm-cocking, acceleration, deceleration, follow-through) will be discussed..$^{20,25,28-30,75}$

As the shoulder rapidly approaches maximum external rotation during the arm cocking phase, a large internal rotation torque acts to prevent the shoulder from overrotating. ${ }^{20,24,26,29,75,86}$ There is also a large horizontal adduction torque produced at this time to prevent uncontrolled horizontal abduction. ${ }^{20,24,86}$ Additionally, the glenohumeral joint undergoes large anterior and superior shear forces as the joint reaches maximum external rotation..$^{20,24,25,28,29,86}$ At the elbow, a large varus torque is produced to counteract the valgus torque exerted on the elbow as the shoulder reaches maximum external rotation. ${ }^{20,24,25,28-30,75,85,86}$ As the shoulder reaches maximum external rotation the elbow begins to extend and elbow flexion torque begins to increase in order to control the rate of elbow extension. $^{20,24,75,86}$

During the acceleration phase the compressive force acting at the shoulder begins to rapidly increase in order to resist distraction of the glenohumeral joint as the arm is propelled forward. ${ }^{20,24,30,86}$ External rotation torque, horizontal adduction torque, and anterior and superior forces at the shoulder all decrease rapidly during this phase. ${ }^{24,86}$ Elbow varus torque also decreases rapidly during this phase as the shoulder internally rotates and moves forward. ${ }^{24,75,86}$ Peak elbow flexion torque is generated in order to control the rapid elbow extension, resulting in generation of a large compressive force at the elbow in order to resist elbow joint distraction..$^{20,24,25,28-30,75,86}$ 
Of the final two phases in the pitching motion, the highest joint kinetics are recorded immediately after ball release at the start of the arm deceleration phase. ${ }^{24,28,86}$ During this critical moment peak compressive force at the shoulder is produced in order to counteract the massive distraction force put on the shoulder as it rotates forward and across the body. ${ }^{20,24,25,28,29,86}$ Peak compressive force at the elbow is generated at this moment for exactly the same reason..$^{20,24,25,28,29,75,86}$ As the deceleration phase continues horizontal abduction torque increases until it reaches its peak at maximum shoulder internal rotation (end of the deceleration phase). ${ }^{20,24,28,29,86}$ This torque acts to prevent uncontrolled horizontal adduction as the arm crosses the body. ${ }^{20}$ Shoulder posterior force and inferior force also increase steadily until they reach their peak shortly before maximum shoulder internal rotation. ${ }^{20,24,25,28,29,86}$ After maximum shoulder internal rotation is reached the follow-through phase begins. ${ }^{18,28,55,61,75}$ During the follow-through phase all upper-extremity joint kinetics return to baseline as the pitcher's motion comes to a rest. ${ }^{24,28,75,86}$

\section{Biomechanical Factors Contributing to Injury}

Pathomechanics of Medial Elbow Injuries

As previously mentioned, the highly dymanic and violent nature of the pitching motion places large stresses on the elbow, particularly on the medial aspect of the joint. $^{5,12,24,28,32-34,37,38,41,42,44,45,51,75,77,83}$ Injuries that are of particular concern to this article include ulnar collateral ligament (UCL) sprains, flexor-pronator muscle mass strains, and ulnar neuritis. $^{12,24,28,33,37,44,51,83}$

During the late arm-cocking phase the elbow is subject to a large valgus torque which causes distraction of the medial elbow joint. ${ }^{20,24,25,28-30,75,85,86}$ Specifically, it has 
been shown that increased valgus torque at the moment of maximum glenohumeral external rotation is associated with an increased risk for elbow injury. ${ }^{5}$ This valgus torque is commonly cited as being around $64 \mathrm{~N}-\mathrm{m}$ but has been measured to be as high as 100$120 \mathrm{~N}-\mathrm{m} . .^{24,37,42,75,77}$ Tension of the UCL creates a varus torque that in part counteracts this large valgus stress. ${ }^{24,28,37,42,75}$ However, cadaver studies have shown that with the elbow flexed to $90^{\circ}$ (the typical position of the elbow during the late arm-cocking phase) the UCL only provides $54 \%$ of this varus torque. ${ }^{33,56}$ It has also been demonstrated that the UCL can only produce a maximum varus torque of $32.1 \pm 9.6 \mathrm{~N}-\mathrm{m}$ before failing. ${ }^{24,28,37,42}$ This means that if the assumption of $64 \mathrm{~N}-\mathrm{m}$ of valgus torque during the late arm-cocking phase is accurate, then the $54 \%$ contribution of the UCL is near the maximum capacity before tissue failure on every pitch. ${ }^{12,24,28,37,42}$ This large tensile stress placed on the UCL during every pitch can lead to cumulative microtrauma and degeneration of the ligament, resulting in stretching or complete tears of the ligament over time..$^{12,24,28,37,38,42,44,51,63,77,83}$

The flexor-pronator muscle mass is also a common site of injury on the medial elbow. ${ }^{12,28,33,37,44,51}$ This group of five muscles acts as a dynamic stabilizer against valgus stress at the elbow joint, with the flexor carpi ulnaris and flexor digitorum superficialis being recognized as the primary dynamic stabilizers. ${ }^{12,37,40,62}$ Contraction of the flexorpronator mass at the end of the arm-cocking phase, along with stability provided by the bony articulation, helps to generate the $46 \%$ of the varus torque not provided by the UCL. ${ }^{12,24,28,37,56}$ This repetitive, high-intensity contraction on every pitch can lead to chronic tendinopathies, such as medial epicondylitis. ${ }^{12,37,44}$ Additionally, if the valgus torque generated during the pitch exceeds the contractile strength of the flexor-pronator 
muscles it can cause acute muscle strains or ruptures. ${ }^{12,37,44,51}$ It has been shown that pitchers with insufficiency of the UCL, defined as damage to the UCL sufficient enough to require surgery, also present with weakness of their flexor-pronator muscles, indicating that either the muscle group is commonly injured concurrently with UCL injury or that a lack of contractile strength of the flexor-pronator muscles can predispose the medial elbow to further injury. ${ }^{34}$

The ulnar nerve is also subject to injury due to the large tensile forces placed on the medial elbow during the late arm-cocking phase and transition into the arm acceleration phase. ${ }^{12,28,37,44}$ The large valgus stress followed by rapid elbow extension places the ulnar nerve under tension and can lead to inflammation of the nerve with repetitive throwing. ${ }^{12,28,37,44}$ The ulnar nerve can also be damaged secondary to injury of the UCL or flexor pronator-mass. ${ }^{12,37}$ Rupture or insufficiency of the UCL can cause hypermobility of the ulnar nerve, causing it to discolate out of the cubital tunnel and become irritated and damaged. ${ }^{12,37,44}$ Microtrauma to the UCL or flexor-pronator mass from pitching can cause soft-tissue adhesions or osteophyte formation which can compress and damage the ulnar nerve within the cubital tunnel. ${ }^{12,28,37,44,51}$ Since the ulnar nerve exits the cubital tunnel between the two heads of the flexor carpi ulnaris, hypertrophy of the flexor-pronator mass and in particular the flexor carpi ulnaris can cause compression of the ulnar nerve. ${ }^{12,44}$

Pathomechanics of Shoulder Injuries

The glenohumeral joint is placed under extremely high forces and loads during multiple parts of the pitching motion. ${ }^{1,24,28,85}$ The accumulation of these kinetics can 
contribute to a variety of shoulder injuries, including superior labrum anterior-posterior (SLAP) tears, rotator cuff strains, and subacromial impingement. ${ }^{3,9,24,28,47,50,54,55,81,82}$

The glenoid labrum deepens the glenoid fossa and provides a more stable surface for the humeral head to articulate with. ${ }^{15,36,71,80}$ Excessive translation and compression of the humeral head on the glenoid labrum can cause tearing or fraying of the labrum. ${ }^{24,28,54,55}$ During the arm-cocking phase large anterior/superior forces are generated as the humerus moves into external rotation..$^{20,24,25,28,29,86}$ If these forces are too high, translation of the humeral head can occur, potentially causing labral tears. ${ }^{24,28,54}$ During the arm acceleration phase, the humerus rapidly internally rotates and a large compressive force acts on the glenohumeral joint to prevent joint distraction. ${ }^{20,24,30,86}$ The combination of this compressive force and rapid internal rotation can cause what is known as the "shoulder grinding factor", in which the humeral head grinds against the glenoid labrum potentially causing a tear. ${ }^{24,28,76}$ The arm deceleration phase is another critical moment with the potential to create labral tears. ${ }^{28,54,76}$ During this phase the shoulder is subject to a peak compressive force in combination with rising posterior/inferior shear forces and rapid internal rotation of the humerus. ${ }^{20,24,25,28,29,86}$ The combination of these forces again creates a shoulder grinding factor and the potential for labral tearing. ${ }^{24,28,76}$

SLAP tears occur at the insertion of the long head of the biceps tendon to the glenoid labrum near the supraglenoid tubercle. ${ }^{3,50,54,81}$ Large forces transmitted through the biceps tendon put tension on this insertion point and can eventually pull the labrum away from the glenoid. ${ }^{3,9,24,28,50,54,55}$ At the end of the arm-cocking phase when maximum glenohumeral external rotation is achieved the long head of the biceps tendon is twisted, 
which alters the line of pull of the biceps. ${ }^{9,55}$ In this position the biceps helps to internally rotate the humerus and tension in the tendon contributes to the large internal rotation torque generated at this moment to prevent excessive external rotation. ${ }^{3,9,50,55}$ The tension on the biceps anchor increases as the arm transitions into the acceleration phase, with the biceps contracting to internally rotate the humerus, compressing the humeral head within the glenoid, and eccentrically controling elbow extension..$^{3,9,21,24,28,43,54,55}$ This excessive torsion placed on the labrum by the contraction of the twisted biceps tendon during the transition from the late arm-cocking to the early arm-acceleration phase is known as the "peel-back" mechanism. ${ }^{9,50,81}$ SLAP tears are also theorized to occur during the arm deceleration phase. ${ }^{3,9,24,28,50,54}$ During this phase biceps muscle activity has been shown to be very high during the deceleration and follow-through phases. ${ }^{21,43}$ Peak compressive force is generated during the deceleration phase in part due to contraction of the biceps, which acts as a dynamic stabilizer to prevent distraction at the glenohumeral joint. $^{21,24,28,50,54}$ Additionally, the biceps continues to eccentrically contract to control elbow extension. ${ }^{3,9,21,24,28,54,55}$ The high muscle activity of the biceps causes tension in the long head of the biceps tendon, which is transmitted to its insertion on the labrum and can cause a SLAP lesion. ${ }^{3,9,24,28,50,54,55}$

Rotator cuff tears in overhead athletes generally occur between the posterior midsupraspinatus and mid-infraspinatus area. ${ }^{24,28,81}$ It is believed that these tears occur due to tensile overload from the large eccentric force generated by these muscles during the deceleration phase of the throwing motion. ${ }^{21,24,28,47,55,76,81,82}$ During this phase there is distraction, horizontal adduction, and internal rotation of the glenohumeral joint. ${ }^{28,55,61}$ The posterior rotator cuff muscles are highly active during this phase as they contract 
eccentrically in order to generate a counter-acting compressive force, a horizontal abduction torque, and to control the rate of internal rotation. ${ }^{21,24,28,55}$ This repetitive high tensile load placed on the posterior rotator cuff can lead to partial or full-thickness tears of the muscle. ${ }^{21,24,28,47,55,76,81,82}$

Subacromial impingement is a condition in which narrowing of the subacromial space causes the compression of one or more suprahumeral structures against the undersurface of the acromion and the coracoacromial ligament. ${ }^{28,81,82}$ The most common suprahumeral structures involved include the tendons of the supraspinatus and infraspinatus muscles, the long head of the biceps tendon, and the subacromial bursa. ${ }^{28,81}$ Subacromial impingement symptoms are often exacerbated with the arm in a position of flexion, horizontal adduction, and internal rotation due to the narrowing of the subacromial space in this position. ${ }^{24,28,55}$ During the arm deceleration phase, the humerus is in a position of forward flexion while it rapidly horizontally adducts and internally rotates across the body. ${ }^{24,28,55} \mathrm{~A}$ large inferior force must be generated during this phase to prevent superior translation of the humeral head..$^{24,28,55}$ Inability to produce this inferior force could lead to subacromial impingement as the humeral head migrates superiorly and compresses the subacromial space..$^{24,28,55}$ Influence of Pitch Type and Velocity on Joint Kinetics

The type of pitch thrown by the pitcher can have a large impact on kinetics at the elbow and shoulder joints and thus injury risk. ${ }^{19,27,31,52,58}$ It was long believed that throwing breaking balls, such as curveballs and sliders, imparted more stress on the throwing arm and put the pitcher at higher risk for injury. ${ }^{26,27,46}$ Preliminary research indicated that among youth pitchers the curveball was associated with an increased risk 
of shoulder pain and the slider was associated with an increased risk of elbow pain. ${ }^{52}$ These beliefs and research have led to youth guidelines that recommend against throwing breaking balls until a certain age is reached. ${ }^{46,74}$ However, biomechanical research examining the actual joint kinetics generated during various pitch types has shown that breaking pitches may not necessarily impart more stress on the shoulder and elbow joints compared to other types of pitches. ${ }^{19,31,58}$

At the elbow, varus torque was actually found to be lower for the curveball when compared to the fastball during the late arm-cocking phase. ${ }^{19,58}$ Additionally, the curveball produced lower elbow flexion torque and elbow proximal force during the arm acceleration phase than the fastball. ${ }^{19,31}$ Shoulder internal rotation torque during the armcocking phase was shown to be higher for the fastball than the curveball. ${ }^{19,58}$ During the arm acceleration phase, shoulder proximal force was also higher for the fastball compared to the curveball. ${ }^{19}$ The results of these studies indicate that the fastball and not the curveball as previously believed may put more stress on the shoulder and elbow joints and increase the risk of injury. ${ }^{19,58}$ Interestingly, for all of the previously mentioned kinetic variables the change-up produced significantly lower values than either the fastball or curveball, indicating that it may be the least stressful pitch on the arm. ${ }^{19,31,58}$

Elbow and shoulder joint kinetics are not only affected by the type of pitch thrown but also by the velocity of the pitch. ${ }^{10,25,41,68}$ Ball velocity has also been shown to be associated with altered kinematic and temporal variables, indicating that variations in pitching mechanics can alter ball velocity. ${ }^{22,25,53,68,69,78}$ Elbow varus torque and shoulder anterior force during the late arm-cocking phase increased along with ball velocity as pitchers increased their effort level. ${ }^{25}$ Additionally, shoulder and elbow compressive 
force has been shown to increase within subjects as pitchers increase their ball velocity. ${ }^{25,68}$ Elbow varus torque, elbow compressive force, shoulder anterior force, and shoulder compressive force have all been shown to increase significantly along with ball

velocity as competition level increased. ${ }^{29}$ Ball velocity was also positively correlated with elbow varus torque in a group of uninjured high school pitchers. ${ }^{41}$ Finally, increased ball velocity has been shown to be associated with a significantly higher risk of elbow injury in professional baseball pitchers and with both shoulder and elbow injuries in adolescent pitchers. ${ }^{10,59}$

\section{Summary}

Baseball pitching places large forces and torques on both the elbow and shoulder joints. These increased joint kinetics have been linked with a variety of elbow and shoulder injuries. Many risk factors for increased kinetics and injuries in overhead throwers have been identified, however the link between ball velocity and elbow and shoulder kinetics is less established. A strong correlation between joint kinetics and velocity might indicate that pitchers who throw at higher velocities are at an increased risk for injury. Conversely, if there is little correlation between ball velocity and elbow and shoulder kinetics it may indicate that pitchers are utilizing efficient mechanics that reduce the chance of injury. While a positive association between elbow varus torque and ball velocity was found in a group of high school pitchers, little research has been done with more elite pitchers or to examine the relationship between shoulder kinetics and ball velocity. Therefore, the purpose of this study was to investigate the relationship of ball velocity with elbow valgus torque, shoulder external rotation torque, and shoulder distraction force in a group of Division 1 collegiate baseball pitchers. 


\section{REFERENCES}

1. Altchek D, Dines D. Shoulder Injuries in the Throwing Athlete. The Journal of the American Academy of Orthopaedic Surgeons. 1995;3(3):159-165.

2. Amis AA, Miller JH. The elbow. Clinics in rheumatic diseases. 1982;8(3):571-93.

3. Andrews JR, Carson WG, McLeod WD. Glenoid labrum tears related to the long head of the biceps. The American journal of sports medicine. 1985;13(5):337-41.

4. Andrews JR, Wilk KE, Satterwhite YE, Tedder JL. Physical examination of the thrower's elbow. The Journal of orthopaedic and sports physical therapy. 1993;17(6):296-304.

5. Anz AW, Bushnell BD, Griffin LP, Noonan TJ, Torry MR, Hawkins RJ. Correlation of torque and elbow injury in professional baseball pitchers. The American journal of sports medicine. 2010;38(7):1368-74.

6. Bigliani LU, Codd TP, Connor PM, Levine WN, Littlefield M a, Hershon SJ. Shoulder motion and laxity in the professional baseball player. The American journal of sports medicine. 1997;25(5):609-13.

7. Borsa PA, Dover GC, Wilk KE, Reinold MM. Glenohumeral range of motion and stiffness in professional baseball pitchers. Medicine and science in sports and exercise. 2006;38(1):21-6.

8. Borsa PA, Laudner KG, Sauers EL. Mobility and stability adaptations in the shoulder of the overhead athlete: a theoretical and evidence-based perspective. Sports medicine. 2008;38(1):17-36.

9. Burkhart SS, Morgan CD, Kibler W Ben. The disabled throwing shoulder: spectrum of pathology Part I: pathoanatomy and biomechanics. Arthroscopy. 2003;19(4):40420 .

10. Bushnell BD, Anz AW, Noonan TJ, Torry MR, Hawkins RJ. Association of maximum pitch velocity and elbow injury in professional baseball pitchers. The American journal of sports medicine. 2010;38(4):728-32. 
11. Cain EL, Andrews JR, Dugas JR, et al. Outcome of ulnar collateral ligament reconstruction of the elbow in 1281 athletes: Results in 743 athletes with minimum 2-year follow-up. The American journal of sports medicine. 2010;38(12):2426-34.

12. Cain EL, Dugas JR, Wolf RS, Andrews JR. Elbow injuries in throwing athletes: a current concepts review. The American journal of sports medicine. 2003;31(4):621-35.

13. Conte S, Requa RK, Garrick JG. Disability days in major league baseball. The American journal of sports medicine. 2001;29(4):431-6.

14. Crockett HC, Gross LB, Wilk KE, et al. Osseous adaptation and range of motion at the glenohumeral joint in professional baseball pitchers. The American journal of sports medicine. 2002;30(1):20-6.

15. Culham E, Peat M. Functional anatomy of the shoulder complex. The Journal of orthopaedic and sports physical therapy. 1993;18(1):342-50.

16. Davis JT, Limpisvasti O, Fluhme D, et al. The effect of pitching biomechanics on the upper extremity in youth and adolescent baseball pitchers. The American journal of sports medicine. 2009;37(8):1484-91.

17. Dick R, Sauers EL, Agel J, et al. Descriptive epidemiology of collegiate men's baseball injuries: National Collegiate Athletic Association Injury Surveillance System, 1988-1989 through 2003-2004. Journal of athletic training. 2007;42(2):183-93.

18. Dillman CJ, Fleisig GS, Andrews JR. Biomechanics of pitching with emphasis upon shoulder kinematics. The Journal of orthopaedic and sports physical therapy. 1993;18(2):402-8.

19. Dun S, Loftice J, Fleisig GS, Kingsley D, Andrews JR. A biomechanical comparison of youth baseball pitches: is the curveball potentially harmful? The American journal of sports medicine. 2008;36(4):686-92.

20. Escamilla R, Barrentine S. Pitching biomechanics as a pitcher approaches muscular fatigue during a simulated baseball game. The American journal of sports medicine. 2007;35(1):23-33.

21. Escamilla RF, Andrews JR. Shoulder muscle recruitment patterns and related biomechanics during upper extremity sports. Sports medicine. 2009;39(7):569-90. 
22. Escamilla RF, Fleisig GS, Zheng N, Barrentine SW, Andrews JR. Kinematic comparisons of 1996 Olympic baseball pitchers. Journal of sports sciences. 2001;19(9):665-76.

23. Ferrari DA. Capsular ligaments of the shoulder. Anatomical and functional study of the anterior superior capsule. The American journal of sports medicine. 1990;18(1):20-4.

24. Fleisig G, Andrews J. Kinetics of baseball pitching with implications about injury mechanisms. The American journal of sports medicine. 1995;23(2):233-9.

25. Fleisig G, Zheng N, Barrentine S, Escamilla R, Andrews J, Lemak L. Kinematic and Kinetic Comparison of Full-Effort and Partial-Effort Baseball Pitching. In: 20th Annual Meeting of American Society of Biomechanics. Atlanta, GA; 1996.

26. Fleisig GS, Andrews JR, Cutter GR, et al. Risk of serious injury for young baseball pitchers: a 10-year prospective study. The American journal of sports medicine. 2011;39(2):253-7.

27. Fleisig GS, Andrews JR. Prevention of elbow injuries in youth baseball pitchers. Sports health. 2012;4(5):419-24.

28. Fleisig GS, Barrentine SW, Escamilla RF, Andrews JR. Biomechanics of overhand throwing with implications for injuries. Sports medicine (Auckland, N.Z.). 1996;21(6):421-37.

29. Fleisig GS, Barrentine SW, Zheng N, Escamilla RF, Andrews JR. Kinematic and kinetic comparison of baseball pitching among various levels of development. Journal of biomechanics. 1999;32(12):1371-5.

30. Fleisig GS, Bolt B, Fortenbaugh D, Wilk KE, Andrews JR. Biomechanical comparison of baseball pitching and long-toss: implications for training and rehabilitation. The Journal of orthopaedic and sports physical therapy. 2011;41(5):296-303.

31. Fleisig GS, Kingsley DS, Loftice JW, et al. Kinetic comparison among the fastball, curveball, change-up, and slider in collegiate baseball pitchers. The American journal of sports medicine. 2006;34(3):423-30.

32. Floris S, Olsen B, Dalstra M. The medial collateral ligament of the elbow joint: Anatomy and kinematics. Journal of shoulder and elbow surgery. 1998;7(4):345351 .

33. Fornalski S, Gupta R, Lee TQ. Anatomy and biomechanics of the elbow joint. Techniques in hand \& upper extremity surgery. 2003;7(4):168-78. 
34. Glousman RE, Barron J, Jobe FW, Perry J, Pink M. An electromyographic analysis of the elbow in normal and injured pitchers with medial collateral ligament insufficiency. The American journal of sports medicine. 1992;20(3):311-7.

35. Guerra J, Timmerman L. Clinical anatomy, histology, and pathomechanics of the elbow in sports. Operative Techniques in Sports Medicine. 1996;4(2):69-76.

36. Halder AM, Itoi E, An KN. Anatomy and biomechanics of the shoulder. The Orthopedic clinics of North America. 2000;31(2):159-76.

37. Hariri S, Safran MR. Ulnar collateral ligament injury in the overhead athlete. Clinics in sports medicine. 2010;29(4):619-44.

38. Hechtman KS, Zvijac JE, Wells ME, Botto-van Bemden A. Long-term results of ulnar collateral ligament reconstruction in throwing athletes based on a hybrid technique. The American journal of sports medicine. 2011;39(2):342-7.

39. Hsu HC, Luo ZP, Cofield RH, An KN. Influence of rotator cuff tearing on glenohumeral stability. Journal of shoulder and elbow surgery. 1997;6(5):41322 .

40. Hsu SH, Moen TC, Levine WN, Ahmad CS. Physical examination of the athlete's elbow. The American journal of sports medicine. 2012;40(3):699-708.

41. Hurd WJ, Jazayeri R, Mohr K, Limpisvasti O, Elattrache NS, Kaufman KR. Pitch velocity is a predictor of medial elbow distraction forces in the uninjured high school-aged baseball pitcher. Sports health. 2012;4(5):415-8.

42. Hurd WJ, Kaufman KR, Murthy NS. Relationship between the medial elbow adduction moment during pitching and ulnar collateral ligament appearance during magnetic resonance imaging evaluation. The American journal of sports medicine. 2011;39(6):1233-7.

43. Jobe FW, Moynes DR, Tibone JE, Perry J. An EMG analysis of the shoulder in pitching. A second report. The American journal of sports medicine. 1984;12(3):218-20.

44. Jobe FW, Nuber G. Throwing injuries of the elbow. Clinics in sports medicine. 1986;5(4):621-36.

45. Jobe FW, Stark H, Lombardo SJ. Reconstruction of the ulnar collateral ligament in athletes. The Journal of bone and joint surgery. American volume. 1986;68(8):1158-63. 
46. Kerut EK, Kerut DG, Fleisig GS, Andrews JR. Prevention of arm injury in youth baseball pitchers. The Journal of the Louisiana State Medical Society $\square$ : official organ of the Louisiana State Medical Society. 2008;160(2):95-8.

47. Kibler W, Kuhn JE, Wilk K, et al. The disabled throwing shoulder: spectrum of pathology-10-year update. Arthroscopy $\square$ : the journal of arthroscopic \& related surgery. 2013;29(1):141-161.e26.

48. Kibler W, Sciascia AD. Current concepts: scapular dyskinesis. British journal of sports medicine. 2010;44:300-305.

49. Kibler W. The role of the scapula in athletic shoulder function. The American journal of sports medicine. 1998;26(2):325-37.

50. Knesek M, Skendzel JG, Dines JS, Altchek DW, Allen A a, Bedi A. Diagnosis and Management of Superior Labral Anterior Posterior Tears in Throwing Athletes. The American journal of sports medicine. 2013;41(2):444-460.

51. Limpisvasti O, ElAttrache NS, Jobe FW. Understanding shoulder and elbow injuries in baseball. The Journal of the American Academy of Orthopaedic Surgeons. 2007;15(3):139-47.

52. Lyman S, Fleisig GS, Andrews JR, Osinski ED. Effect of pitch type, pitch count, and pitching mechanics on risk of elbow and shoulder pain in youth baseball pitchers. The American journal of sports medicine. 2002;30(4):463-8.

53. Matsuo T, Escamilla R, Fleisig G, Barrentine S, Andrews J. Comparison of kinematic and temporal parameters between different pitch velocity groups. Journal of applied biomechanics. 2001;17:1-13.

54. McLeod WD, Andrews JR. Mechanisms of shoulder injuries. Physical therapy. 1986;66(12):1901-4.

55. Meister K. Injuries to the shoulder in the throwing athlete. Part one:

Biomechanics/pathophysiology/classification of injury. The American journal of sports medicine. 2000;28(2):265-75.

56. Morrey BF, An KN. Articular and ligamentous contributions to the stability of the elbow joint. The American journal of sports medicine. 1983;11(5):315-9.

57. NCAA. Student-Athlete Participation: 1981-1982 - 2010-11. 2011.

58. Nissen CW, Westwell M, Ounpuu S, Patel M, Solomito M, Tate J. A biomechanical comparison of the fastball and curveball in adolescent baseball pitchers. The American journal of sports medicine. 2009;37(8):1492-8. 
59. Olsen SJ, Fleisig GS, Dun S, Loftice J, Andrews JR. Risk factors for shoulder and elbow injuries in adolescent baseball pitchers. The American journal of sports medicine. 2006;34(6):905-12.

60. Osbahr DC, Cannon DL, Speer KP. Retroversion of the humerus in the throwing shoulder of college baseball pitchers. The American journal of sports medicine. 2002;30(3):347-53.

61. Pappas AM, Zawacki RM, Sullivan TJ. Biomechanics of baseball pitching. A preliminary report. The American journal of sports medicine. 1985;13(4):216-22.

62. Park MC, Ahmad CS. Dynamic contributions of the flexor-pronator mass to elbow valgus stability. The Journal of bone and joint surgery. 2004;86-A(10):2268-74.

63. Petty DH, Andrews JR, Fleisig GS, Cain EL. Ulnar collateral ligament reconstruction in high school baseball players: clinical results and injury risk factors. The American journal of sports medicine. 2003;32(5):1158-64.

64. Pieper HG. Humeral torsion in the throwing arm of handball players. The American journal of sports medicine. 1998;26(2):247-53.

65. Posner M, Cameron KL, Wolf JM, Belmont PJ, Owens BD. Epidemiology of Major League Baseball injuries. The American journal of sports medicine. 2011;39(8):1676-80.

66. Reagan KM, Meister K, Horodyski MB, Werner DW, Carruthers C, Wilk K. Humeral retroversion and its relationship to glenohumeral rotation in the shoulder of college baseball players. The American journal of sports medicine. 2002;30(3):354-60.

67. Steinbeck J, Liljenqvist U, Jerosch J. The anatomy of the glenohumeral ligamentous complex and its contribution to anterior shoulder stability. Journal of shoulder and elbow surgery. 1998;7(2):122-6.

68. Stodden DF, Fleisig GS, McLean SP, Andrews JR. Relationship of biomechanical factors to baseball pitching velocity: within pitcher variation. Journal of applied biomechanics. 2005;21(1):44-56.

69. Stodden DF, Fleisig GS, McLean SP, Lyman S, Andrews JR. Relationship of pelvis and upper torso kinematics to pitched baseball velocity. Journal of applied biomechanics. 2001;17:164-172.

70. Stroyan M, Wilk KE. The functional anatomy of the elbow complex. The Journal of orthopaedic and sports physical therapy. 1993;17(6):279-88. 
71. Terry GC, Chopp TM. Functional anatomy of the shoulder. Journal of athletic training. 2000;35(3):248-55.

72. Terry GC, Hammon D, France P, Norwood LA. The stabilizing function of passive shoulder restraints. The American journal of sports medicine. 1991;19(1):26-34.

73. USA Baseball. Final Report. 2009. Available at: http://web.usabaseball.com/downloads/2009/final_report.txt.

74. Valovich McLeod TC, Decoster LC, Loud KJ, et al. National Athletic Trainers' Association position statement: prevention of pediatric overuse injuries. Journal of athletic training. 2011;46(2):206-20.

75. Werner SL, Fleisig GS, Dillman CJ, Andrews JR. Biomechanics of the elbow during baseball pitching. The Journal of orthopaedic and sports physical therapy. 1993;17(6):274-8.

76. Werner SL, Guido JA, Stewart GW, McNeice RP, VanDyke T, Jones DG. Relationships between throwing mechanics and shoulder distraction in collegiate baseball pitchers. Journal of shoulder and elbow surgery. 2007;16(1):37-42.

77. Werner SL, Murray TA, Hawkins RJ, Gill TJ. Relationship between throwing mechanics and elbow valgus in professional baseball pitchers. Journal of shoulder and elbow surgery. 2002;11(2):151-5.

78. Werner SL, Suri M, Guido J a, Meister K, Jones DG. Relationships between ball velocity and throwing mechanics in collegiate baseball pitchers. Journal of shoulder and elbow surgery. 2008;17(6):905-8.

79. Whiteley R. Baseball throwing mechanics as they relate to pathology and performance-A review. Journal of Sports Science and Medicine. 2007;(6):1-20.

80. Wilk KE, Arrigo C a, Andrews JR. Current concepts: the stabilizing structures of the glenohumeral joint. The Journal of orthopaedic and sports physical therapy. 1997;25(6):364-79.

81. Wilk KE, Obma P, Simpson CD, Cain EL, Dugas JR, Andrews JR. Shoulder injuries in the overhead athlete. The Journal of orthopaedic and sports physical therapy. 2009;39(2):38-54.

82. Williams GR, Kelley M. Management of rotator cuff and impingement injuries in the athlete. Journal of athletic training. 2000;35(3):300-15.

83. Williams RJ, Urquhart ER, Altchek DW. Medial collateral ligament tears in the throwing athlete. Instructional course lectures. 2004;53:579-86. 
84. Wuelker N, Korell M, Thren K. Dynamic glenohumeral joint stability. Journal of shoulder and elbow surgery. 1998;7(1):43-52.

85. Zheng N, Barrentine SW. Biomechanics and motion analysis applied to sports. Physical medicine and rehabilitation clinics of North America. 2000;11(2):30922.

86. Zheng N, Fleisig GS, Barrentine SW, Andrews JR. Biomechanics of Pitching. In: Hung G, Pallis J, eds. Biomedical Engineering Principles in Sports. 1st ed. Kluwer Academic/Plenum Publishers; 2004:209-256. 